\title{
El patrimonio bibliográfico a través de los museos y exposiciones virtuales: análisis y descripción del contenido
}

\author{
José Luis Herrera Morillas
}

Universidad de Extremadura

\section{1. Resumen}

Análisis y descripción del contenido de páginas web sobre exposiciones y museos de colecciones bibliográficas antiguas, en las que participan centros bibliotecarios, museos y otras instituciones, principalmente, de Europa y Estados Unidos. Se han localizado 135 lugares de interés, 122 sobre exposiciones y 13 sobre museos. Después de clasificar estos recursos, se describe un ejemplo de cada tipo.

Palabras clave: Exposiciones virtuales. Museos virtuales. Patrimonio bibliográfico. Fondo antiguo. Internet.

\section{2. Abstract}

A series of webs related to exhibitions and museums of old bibliographical collections, in which take part librarys, museums and other institutions mainly in Europe and the United States, are analyzed. 135 websites of interest, 122 about exhibitions and 13 about museums have been located. After classifying these resources, an example of each kind is described.

Keywords: Virtual exhibitions. Virtual museum. Bibliographic heritage. Old collections. Internet.

\section{Introducción}

Los recursos de interés para el estudio y el acceso al libro antiguo a través de Internet son incontables en la actualidad. "La consulta de este tipo de documentos y su investigación se ha visto favorecida con la aparición y difusión de Internet y las tecnologías de digitalización de tal forma que en la actualidad es posible acceder a libros y manuscritos que hasta el momento sólo podrían consultarse en las bibliotecas en los que están depositados" (Velasco, 2000). En este estudio nos hemos centrado en una importante faceta de los recursos citados: las 
exposiciones y museos virtuales, iniciativas en alza, debido a que "exponer un libro antiguo es contribuir en la tarea educativa y cultural intrínseca a los objetivos de cualquier biblioteca. Pero además es una forma de atraer la atención dando a conocer el patrimonio, su valor artístico, motivando de esta forma a que sea respetado y por tanto mejor conservado" (Rosales, 2000, p. 301). Estas nuevas muestras virtuales están vinculadas a las clásicas exposiciones bibliográficas presenciales que, junto a la publicación de catálogos, han sido hasta el momento las dos vías más generalizadas para la difusión del fondo antiguo de las bibliotecas. Desde el punto de vista de los estudios de colecciones bibliográficas antiguas, es prioritario aprovechar las ventajas de las nuevas tecnologías, ya que facilitan un acceso a documentos originales, de una forma rápida y flexible (Santos, 1999).

Entre los objetivos de este trabajo está mostrar una selección de páginas web sobre museos y exposiciones virtuales de fondo antiguo, describirlas y aportar los datos necesarios para facilitar su localización y consulta. Tarea previa a este trabajo ha sido la búsqueda en Internet de páginas y sitios relacionados con la temática definida. En total hemos localizado 135 lugares de interés.

Otra tarea realizada ha sido la clasificación de estos recursos. Hemos empleado el siguiente esquema de clasificación temático elaborado a partir del contenido de las obras a las que están dedicadas las exposiciones y museos:

I. Exposiciones: mapas y cartografía, música, colecciones — de bibliotecas, de museos, selectivas-, manuscritos — libros manuscritos, documentos varios-, tesoros, de tema histórico, encuadernaciones, monográficas, ilustraciones e iconografía, de un libro.

II. Museos: sobre elaboración del papel, sobre la imprenta

Las exposiciones dedicadas a "Mapas y cartografía" están muy extendidas, en ellas varía el modo de presentar el acceso a las imágenes cartográficas. Por ejemplo, uno de estos modos de acceso es la recuperación de las imágenes a través de un formulario, sistema poco frecuente en exposiciones de otra temática. Las muestras dedicadas a "Música" se centran en música impresa, también suelen contener libros de temática musical. El grupo "Colecciones" podemos considerarlo el más difundido. Entre él abunda uno de los tipos de exposición más ambiciosos, caracterizado porque la muestra no se ciñe a una sola colección, ni a un tema determinado. La riqueza de tipologías documentales, contenidos y disciplinas son algunas de las cualidades que las definen. Las hemos incluido bajo la expresión exposiciones "Selectivas". Con el término "Manuscritos" nos referimos a las exposiciones dedicadas a libros, textos y documentos manuscritos antiguos o también modernos; en este caso, normalmente vinculados a escritores, personajes célebres y acontecimientos históricos. En las exposiciones de "Tesoros" hacemos mención a las que incluyen esta expresión en el título y tienen por contenido obras

Scire. $8: 1$ (en.-jun. 2002) 157-172. 
raras y preciosas. En las de "Tema histórico" agrupamos todas aquéllas que ilustran un tema histórico con obras de carácter bibliográfico; aunque éstas son las mayoritarias, también suelen estar presentes otro tipo de objetos (monedas, obras de arte, etc.). El apartado "Monográficas" lo hemos empleado para reunir exposiciones dedicas a un tema o aspecto específico: libros ilustrados para niños, producción de un determinado impresor, etc. Las muestras denominadas con la expresión "Ilustraciones e iconografía" son aquellas centradas en ilustraciones de libros, normalmente dedicadas a una determinada iconografía o temática (botánica, arquitectura, anatomía, etc.). Finalmente, también hemos localizado muestras virtuales dedicadas exclusivamente a un libro determinado. La principal característica que las diferencia del resto es que suelen reproducir el libro completo.

\section{Ejemplos de exposiciones y museos virtuales}

A continuación presentamos un ejemplo de cada uno de los tipos de exposiciones y museos virtuales establecidos en la clasificación anterior. De cada uno de ellos presentamos estos datos y por este orden: título, URL, lengua, fecha de consulta, institución y contenido. En el contenido diferenciamos los datos que aparecen al inicio de la web a modo de presentación, la sección en la que se muestran las obras expuestas y otros apartados complementarios (introducción, índices, textos complementarios, enlaces, etc.). A los dos primeros elementos los hemos denominado "portada" y "catálogo de obras" respectivamente por la semejanza con los catálogos de exposiciones impresos (para los museos en lugar de "catálogo de obras" hemos empleado la expresión "recorrido por las obras"). En algunas ocasiones también comentamos aspectos relacionados con el diseño de las web.

\subsection{Mapas y cartografía}

- Título: Mapas y planos en el Archivo de la Corona de Aragón.

- URL: http: //www.mcu.es/lab/archivos/mapas/index.html

- Lengua: español.

- Fecha de consulta: 8/11/01.

- Institución: Ministerio de Educación Cultura y Deportes y Archivo Corona de Aragón.

- Contenido: Reúne una selección de la colección de mapas y planos del Archivo de la Corona de Aragón. El plano más antiguo es de 1584, muestra la zona fronteriza entre España y Francia en torno a la laguna Leucata, con la situación de unas salinas objeto de controversia entre las localidades de Salses y Sant Llorenç. Fue realizado en 1584 por Jorge Setara, uno de los ingenieros italianos al servicio de Felipe II. La mayoría de los planos de los siglos XVI y XVII proceden de los legajos de la sección Consejo de Aragón y están en relación con una de las tareas fundamentales del Estado moderno: la defensa del territorio. También se incluyen planos o dibujos de arquitectura relativos a la construcción o reparación de las casas de religiosos, planos de los fondos judiciales que, en el

Scire. $8: 1$ (en.-jun. 2002) 157-172. 
caso del Archivo de la Corona de Aragón, proceden principalmente de dos instituciones: la Real Audiencia y la Bailía General de Cataluña. La portada presenta el título de la muestra y el nombre de la institución organizadora sobre un fondo con motivos cartográficos. La siguiente página es el índice: introducción, exposición, bibliografía y juego. Las obras que componen el catálogo se incluyen cada una en una página independiente, con estos elementos: imagen, título y año (en la parte superior); descripción del contenido y datos catalográficos (en la parte inferior); en el lado derecho hay un índice que permite acceder a una ampliación de un detalle del mapa, notas de interés y documentación relacionada. Se muestran 20 mapas y planos. Finalmente en una página se recogen los créditos de la exposición y en otra, un juego formado por un puzzle sobre un mapa.

\subsection{Música}

- Título: Musicke of sundrie kindes.

- URL: http://special.lib.gla.ac.uk/exhibns/music/musickex.html

- Lengua: inglés.

- Fecha de consulta: 7/11/01.

- Institución: Glasgow University Library.

- Contenido: Recopila obras sobre música de la colección William Euing de los siglos XV al XIX. William Euing, un próspero corredor de seguros de Glasgow, legó tras su muerte en 1874 su biblioteca de 17.000 volúmenes a dos instituciones de Glasgow. Gran parte de la colección correspondió a la Universidad de Glasgow, pero su colección de música estableció que fuera a la Universidad de Anderson (ahora la Universidad de Strathclyde). En 1936 las dos partes de la biblioteca de Euing fueron reunidas cuando la sección de música (que asciende a unos 2500 volúmenes) fue transferida a la Biblioteca de la Universidad de Glasgow. Euing era un entusiasta de la música — participante regular en la sociedad St. Cecilia. Este entusiasmo, combinado con sus conocimientos de experto bibliógrafo dio lugar a la formación de una de las colecciones más ricas de música impresa antigua de Gran Bretaña. Sus tesoros incluyen dos manuscritos litúrgicos medievales; obras del siglo XV, entre los que destaca el Musices opusculum de Nicolaus Burtius, impreso en 1487, raro ejemplo de cuaderno de música impresa; tempranos impresos de música del XVI, italianos y flamencos; algo de las importantes series de publicaciones de música inglesa aparecidas entre 1580 y 1620; ejemplos tempranos de música impresa del XVII; un salterio escocés de fines del XVII y una antología de la canción; un elegante ejemplo de música de cámara francesa del XVIII y destacadas publicaciones de conciertos para orquesta de compositores italianos e ingleses. Esta exposición es una versión virtual de otra presencial que tuvo lugar del 11 de enero al 18 febrero de 1978. El catálogo de obras se organiza en tres apartados dedicados a música vocal sacra; música vocal religiosa; tratados generales y música instrumental. En total incluye información de 58 obras. De cada obra: autor, título, año, texto explicativo y enlaces a los registros de la biblioteca donde se ubica. Se presentan 16 imágenes de los libros. Las imágenes se pueden ampliar. Incluye también un texto de introducción. Toda la exposición se alberga en una sola página. Los registros con los datos de los libros se

Scire. $8: 1$ (en.-jun. 2002) 157-172. 
disponen de modo sucesivo. En la parte superior de la página se recogen los datos propios de la portada: título, ampliación del título y un grabado.

\subsection{Colecciones}

\subsubsection{De bibliotecas}

- Título: Une bibliothèque jesuite: regards sur la colecction des Fontaines.

- URL: http: //www.bm-Lyon.fr/expo/jesuite/chantilly.htm

- Institución: Bibliothèque de Lyon.

- Lengua: francés.

- Contenido: Se muestra una parte de los fondos de la colección "des Fontaines" formada por cerca de 350.000 volúmenes y documentos. Esta colección tiene su origen en la ciudad de Jersey, donde la Compañía se instala en 1880 después de la expulsión de Francia. Tras diversos avatares y recorridos, la colección ha sido transferida a Lyon. En total se exponen unas 62 obras. La portada presenta la siguiente información: una imagen del exterior de la Biblioteca (da acceso a un texto explicativo sobre la historia de la colección), el título y subtítulo de la muestra y el índice general. El catálogo de obras lo forman los apartados II a X del índice. El apartado "Sobre las ediciones", alude a la existencia en la colección de distintas ediciones de una misma obra. Los apartados restantes se refieren a "Imágenes santas" (fondos iconográficos), "Textos sagrados" (Biblia, Torah y Corán), "Los pilares de la fe" (obras de San Jerónimo, Santo Tomás, San Agustín y Martín Lutero), "La piedad en la vida diaria" (Reglas, Sermones y Breviarios), "Manuscritos" (miniatura de la "Visión de la mujer y el Dragón" del Apocalipsis de San Juan, manuscrito del siglo XV), "Un cuaderno de la Biblia de Gutemberg", "Sobre las ciencias y las letras" (tres obras de Ciencias y tres de letras), "Tierra Sínica" (cinco obras de la sección china de esta colección), "De un continente al otro" (nueve ejemplos de obras que alberga la colección, fruto de los viajes misioneros: planos, grabados exóticos de animales salvajes, curiosidades naturales...) y "Al margen" (obras al margen de la doctrina de la Iglesia, magia, soteriología, etc.). Los datos aportados de cada obra son: autor, título, lugar, año, signatura y un breve texto explicativo, también incluye imágenes digitalizadas que se pueden ampliar. Otros elementos: el apartado I del índice reúne datos, información general e imágenes sobre el traslado y la instalación de esta colección en la Biblioteca de Lyon. En el diseño recurre al contraste entre el fondo de las páginas —en negro- y los fragmentos de imágenes — en color-; éstos acompañan a los títulos y epígrafes principales trazados con caracteres de color crema y gris. En la portada, la imagen del exterior de la biblioteca va colocada en la parte superior izquierda, a continuación el título y subtítulo de la muestra. El resto de la página aloja el índice: los términos de éste van precedidos de un rectángulo que contiene fragmentos de ilustraciones de las obras pertenecientes a los fondos de la sección temática respectiva. Este índice ocupa la zona izquierda, en la derecha aparece una figura antigua de un sacerdote jesuita. Todos los apartados que configuran el catálogo de obras, presentan un diseño semejante: encabezado con el título y subtítulo (colores crema y gris), precedido de una ilustración (la misma que aparece en el índice). Las imágenes de las obras se alinean verticalmente en el lado izquierdo; en el centro de la página se dispone un texto explicativo general.

Scire. 8: 1 (en.-jun. 2002) 157-172. 


\subsubsection{De museos}

- Título: Aureum Corpus. Cinco siglos de libros ilustrados.

- URL: http://www.uoc.es/humfil/aureum/index_es.html

- Institución: Museo Frederic Marès de Barcelona.

- Lengua: castellano.

- Fecha de consulta: 1/09/01.

- Contenido: Esta web se ha concebido como un complemento de la exposición del mismo nombre iniciada el 12 de abril del 2000 en el Museo Frederic Marès de Barcelona. Se expone una selección de 90 libros del Museo. El concepto de exposición virtual aparece en el texto de presentación, en el que se indica que "la exposición virtual forma parte de un proyecto de investigación sobre patrimonio, museos y recursos digitales que está desarrollando el grupo OLIBA de los estudios de Humanidades y Filología de la UOC". La portada contiene un texto explicativo de la exposición, una ilustración y el índice general. La parte dedicada a catálogo de obras está formada por tres grupos temáticos: obras de los siglos XIV-XVIII, del siglo XIX y del XX. De cada obra se aporta la referencia bibliográfica (autor, título, ciudad de publicación, impresor y año), un breve comentario y, en algunos casos, una imagen digitalizada, que se puede ampliar abriendo una nueva pantalla. En cada grupo hay algunas obras de las que se han digitalizado todas las ilustraciones (se indica en el listado a través de un icono alusivo). Del primer grupo estas obras son: Ramón Lul, Practica compendiosa artis..., Lyon, Joannis Moylin, 1523 (11 ilustraciones) y Joseph Romeguera, Ateneo de grandesa sobre eminencias cultas catalana facundia ab emblemas ilustrada, Barcelona, Joan Jolis, 1681 (12 xilografías). De las obras del siglo XIX las ilustraciones completas corresponden a: Langlois, M. C., Voyage Pittoresque \& Miniature en Espagne, París, Engelmann, c. 1835; Piferrer, Pablo, Recuerdos y bellezas de España, Principado de Cataluña, Barcelona, Joaquín Verdaguer, 1939; Dumas, Alejandro, El mendigo hipócrita, Barcelona, Imprenta de Joaquín Bosch, 1859; y Dumas, Alejandro, La dama de las Camelias, Barcelona, Trilla y Serra, 1880. De las obras del siglo XX se muestra un mayor fondo de imágenes, están incluidas en estos libros: Pedro Calderón de la Barca, La vida es sueño, Barcelona, La Cometa, Gustavo Gili Editor, 1933 (38 xilografías a color de Enric Cristofol Ricart); Cristóbal Colón, Primer viaje de Cristóbal Colón, Barcelona, Amigos del Libro, 1944 (12 xilografías de Antoni Ollé Pinel); Josep M. Roviralta, Boires baixes, Vilanova i la Geltrú, Oliva, 1902 (10 dibujos a pluma de Lluis Bonnin, 5 partituras y la encuadernación). Otros elementos: acceso virtual a un taller de impresión; listado con información de los grabadores de los libros expuestos; explicación de las técnicas de grabado en impresión usadas en las obras; índice de enlaces a museos e instituciones relacionadas con el mundo de la imprenta y de la ilustración se recogen las direcciones de las páginas web donde se ha encontrado información textual e imágenes, sobre las técnicas de impresión-; se incluye un conjunto de datos históricos sobre esta temática; información referente a Frederic Marès; información sobre este Museo; y, por último, se aportan datos acerca de las publicaciones de la Asociación de Bibliófilos de Barcelona. Con relación al diseño destacan los fondos de las páginas principales — reproducen superficies de madera — y la ornamentación, centrada en gre- 
cas y motivos vegetales. Estas páginas llevan el índice principal en la parte inferior, formado por iconos alusivos al contenido de cada apartado. El centro de la portada está ocupado por tres imágenes; cada una introduce una parte del catálogo. Al pulsarlas se accede a una página con el listado de obras, al inicio y como encabezamiento, aparece la misma imagen que identifica el apartado del catálogo y, en un recuadro bordeado de una greca vegetal, los siglos a los que pertenecen las obras; debajo, un breve texto introductorio y una greca horizontal para delimitar esta parte del listado de obras presentado a continuación. Al pulsar las referencias se despliega un breve texto explicativo y las imágenes digitalizadas.

\subsubsection{Selectivas}

- Título: Ex-libris Universitatis.

- URL: http://busc.usc.es/exlibris/indexlibris.htm

- Institución: REBIUN (Red de Bibliotecas Universitarias Españolas).

- Lengua: castellano.

- Fecha de consulta: 3/09/01.

- Contenido: Es la primera exposición bibliográfica colectiva de REBIUN, nace como un proyecto cooperativo con el fin de dar a conocer el importante patrimonio bibliográfico universitario. La muestra la forman 209 obras: manuscritos e impresos con miniaturas, grabados, mapas y encuadernaciones, pertenecientes a los siglos X al XVIII. Participan 33 universidades españolas, públicas y privadas. Esta exposición virtual es complemento de otra que tuvo lugar en el Colexio Fonseca de Santiago de Compostela del 28 de septiembre al 31 de octubre de 2000. La portada consta del título y subtítulo (éste en castellano y en los demás idiomas de las Comunidades Autónomas españolas) separados por un motivo decorativo. Catálogo de obras (figura 1): la exposición, se divide en cuatro apartados: "Constituciones y Estatutos universitarios" (11 imágenes de 11 obras), "El universo de los códices" (44 imágenes de 36 obras), "En la cuna de la imprenta" (41 imágenes de 38 incunables de Alemania, Italia, Francia, Suiza y España) y "La Librería de la Universidad" (134 imágenes de 124 obras). Este último capítulo dedicado a "La Librería de la Universidad", es el más extenso, con este nombre se denominaba la biblioteca universitaria hasta el siglo XVIII. En trece apartados (Biblia, textos y exégesis; Historia eclesiástica; Historia profana y Biografías; Geografía; Lexicografía y Gramática; Literatura; Medicina, Veterinaria e Historia natural; Astrología y Matemáticas; Bellas Artes: Arquitectura y Artes plásticas, Música y Danza; Arte militar, Técnica e Industria; Filosofía; Derecho; y Nuevos caminos: la información periódica), se expone una selección de las colecciones que las bibliotecas universitarias guardan como testimonio de su función y de su historia. Cada uno de estos capítulos se inicia con un texto y, seguidamente, se disponen los registros de las obras catalogadas según estos datos: autor, título, lugar, impresor, año, descripción física, localización y al menos una imagen digitalizada de una página interior, de una ilustración o de la portada. Las imágenes no se pueden ampliar. Otros elementos: "Presentación" formada por un texto de Darío Villanueva Prieto y por los datos de la Comisión Técnica de la Exposición, "Universidades" (relación de las universidades participantes) y "Créditos".

Scire. 8: 1 (en.-jun. 2002) 157-172. 
El diseño de la portada juega con elementos de grafías antiguas. En el resto de la exposición se utiliza como recurso principal los marcos: el índice general permanece fijo en el lado izquierdo, en la parte central va apareciendo la información seleccionada. El fondo de las páginas es de color blanco, los textos se han realizado con letras de color marrón, para los títulos se usa el rojo, el ocre y para algunas zonas de las páginas el morado.

\subsection{Manuscritos}

\subsubsection{Libros manuscritos}

- Título: Islamic Medical Manuscripts at the National Library of Medicine.

- URL: http://www.nlm.nih.gov/hmd/arabic/catalog_tb.html

- Lengua: inglés.

- Fecha de consulta: 12/11/01.

- Institución: U. S. National Library of Medicine.

- Contenido: Esta exposición, dedicada a mostrar la colección de manuscritos islámicos de la Biblioteca Nacional de Medicina, se ha proyectado en tres fases. En la actualidad se visualiza la primera fase, que cubre cerca de un tercio de los manuscritos islámicos de la citada biblioteca y fue terminada en el año 2000. Las siguientes fases del proyecto irán apareciendo en años sucesivos. El catálogo está formado por cuatro apartados. El primero recoge "traducciones tempranas" de autores como Hipócrates o Galeno, y muestra un total de nueve obras. El siguiente, más extenso, está dedicado a 29 "enciclopedias médicas": El mundo islámico heredó gran parte del conocimiento médico y científico de griegos y romanos, legado al que los médicos y eruditos islámicos agregaron sus nuevos conocimientos y experiencias. Para reunir y transmitir toda esta información crearon las enciclopedias de la ciencia y práctica de la medicina. Con este género de literatura médica sistematizaron un extenso arsenal de fuentes en un formato lógico y accesible. El tercer apartado está dedicado a los "epítomes": las obras de medicina formadas por cientos de páginas eran a menudo

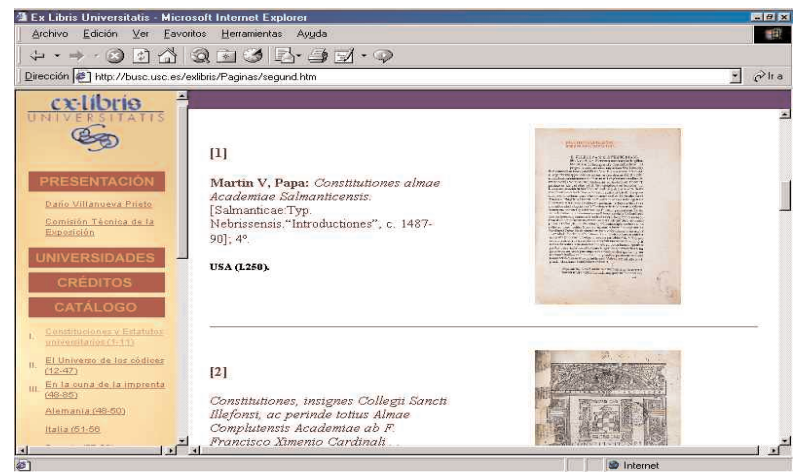

Figura 1. Exposición "Ex-libris Universitatis”.

Scire. 8: 1 (en.-jun. 2002) 157-172. 
costosas de copiar y de difícil manejo en el transcurso de una sesión o clase práctica. Por estas razones, empezaron a ser demandadas las versiones abreviadas y los resúmenes (epítomes). En total se incluyen cinco. El último apartado reúne trece "comentarios": El corpus médico heredado de griegos y romanos resultaba poco metódico y a veces contradictorio, además, el ambiente en el que los árabes practicaban la medicina era muy distinto. Por estas razones los eruditos islámicos se vieron en la necesidad de realizar numerosos y extensos comentarios a las obras de medicina. De todas las libros expuestos se incluye al menos una imagen, un texto explicativo, descripción física, descripción de la encuadernación, procedencia y referencia bibliográfica. En los textos, algunas expresiones y términos enlazan a los apartados glosario, bio-bibliografías y abreviaturas de esta web. Otros apartados son introducción, bio-bibliografías, glosario, abreviaturas y créditos, y una página con enlaces a un lugar sobre exposiciones y programas públicos de historia de la medicina en Internet y a otra web especializada en historia de la medicina. Todas las páginas llevan en la parte superior el título en caracteres árabes y latinos. Destaca el color morado empleado para el fondo del índice general de la web que se visualiza en todas las páginas de la exposición, en contraste con el color arena de los demás fondos.

\subsubsection{Documentos varios}

- Título: Brouillons d'ecrivains.

- URL: http://www.bnf.fr/pages/expos/brouillons/index.htm

- Lengua: francés.

- Fecha de consulta: 9/11/01.

- Institución: Bibliothèque National de France.

- Contenido: Esta exposición se centra en varios manuscritos de los escritores RougonMacquart, Emile Zola, Honoré de Balzac y Raymond Queneau. La sección que podemos considerar como catálogo está diseñada en tres epígrafes: I) Dossiers de l'exposition, se inicia explicando el origen de la expresión "Brouillons", también desarrolla estos aspectos histoire de manuscrits (recorrido del XIV al XX); ateliers d'écrivains (dedicada a autores concretos), fabrique du texte (comenta cuestiones de los textos como el comienzo y el fin, notas, etc.) y écrire aujourd'hui. En todos estos apartados se incluye un texto explicativo e imágenes; algunas palabras del texto son enlaces que amplían la información con otros textos y otras imágenes. II) Dossiers d'ecrivains, extractos de los dossiers preparatorios de Rougon-Macquart y del Assomir de Emile Zola, disponibles en formato texto y audiovisual. III) Pages à explorer, dedicadas a La femme supérieure de Honoré de Balzac y la Traité des vertus deemocratiques de Raymond Queneau, se analizan aspectos como las correcciones realizadas por los autores, etc. Otros apartados: "Pistes pedagogiques" (a partir de un manuscrito de Raymond Queneau y de Émile Zola se profundiza en sus obras), "Recontres" (escritores de hoy dan su opinión sobre la práctica de la escritura en la actualidad) y "Repères" (selección bibliográfica). Los distintos apartados de está web utilizan como recurso abundantes imágenes de los manuscritos, con textos explicativos que a su vez incluyen enlaces para ampliar la información con nuevas imágenes y explicaciones.

Scire. 8: 1 (en.-jun. 2002) 157-172. 


\subsection{Tesoros}

- Titulo: Dresden: Treasures from the Saxon State Library.

- URL: http://www.loc.gov/exhibits/dres/dresintr.html

- Lengua: inglés.

- Fecha de consulta: 5/11/01.

- Institución: Library of Congress.

- Contenido: Dedicada a una de las instituciones culturales más destacadas de Dresde. la "Landesbibliothek", Biblioteca del estado alemán de Saxon, fundado en 1556, cuando el príncipe Elector Augustus comenzó sistemáticamente a adquirir libros doctos y obras literarias. Esta Biblioteca con motivo de su 440 aniversario reúne sus tesoros bibliográficos y los cede a la Biblioteca del Congreso para una muestra inaugurada abril de 1996. El catálogo de las obras se organiza en los siguientes apartados: manuscritos medievales y renacentistas, incunables, la Reforma en Alemania, la Biblia, la Biblioteca Electoral, Encuadernaciones renacentistas, La "Electoral of kapelle", lo más destacado de la centuria, la era augustea, la "Fravenkirche", la era de Goethe y el Romanticismo en Dresde. Cada uno de estos apartados se organiza en una única página que incluye un texto introductorio y, a continuación, las obras. De cada obra se recoge la referencia bibliográfica, enlace a una imagen y comentario. En total se visualizan 58 imágenes de las obras expuestas. En la primera página de la exposición se dispone el título, el índice con todos los contenidos de la muestra y una ilustración.

- Otros apartados: introducción, historia de Dresde, cronología de Dresde, fotografías: vista de Dresde y Staff de la exposición. Finalmente se incluyen dos enlaces: a la web general de la Biblioteca del Congreso y a su página de exposiciones virtuales.

\subsection{De tema histórico}

- Título: Le Roi Charles V et son Temps (1338-1380).

- URL: http: //www.bnf.fr/enluminures/accueil shtm

- Institución: Bibliothèque Nationale de France.

- Lengua: Francés.

- Fecha de consulta: 7/10/01.

- Contenido: Esta web, que alberga 1000 ilustraciones de libros antiguos procedentes del Departamento de Manuscritos de la Biblioteca Nacional de Francia, está dedicada al rey Carlos V. Se inicia con una portada decorada con una ilustración de este monarca, junto al título e información complementaria. No se hace referencia al término exposición, pero su diseño y el hecho de estar incluida en la sección de exposiciones virtuales de la Biblioteca Nacional de Francia prueba la finalidad de esta iniciativa. Estamos ante un ejemplo de las excelentes exposiciones organizadas por la Biblioteca Nacional de Francia dedicadas a ilustrar un tema histórico con fondos bibliográficos. La sección "thèmes" podemos considerarla el catálogo de obras. Incluye la siguiente lista de temas: historia, religión, ciencias y técnicas, deportes y diversiones, diversos. Cada uno de estos términos da acceso a otra lista de subcategorías, que a su vez se subdivide. Esta

Scire. $8: 1$ (en.-jun. 2002) 157-172. 
última lista de términos es la que da acceso a las imágenes de las obras. Otros elementos incluidos son una sección con 17 textos que desarrollan otros tantos temas relacionados con el contenido de la muestra. Estos textos insertan enlaces a las imágenes y, por último, una relación de los manuscritos a los que corresponden las ilustraciones. A ellos se puede acceder pulsando el nombre de cada manuscrito. Presenta un diseño basado en listas con marcas en forma de bola. Los distintos colores de las bolas permiten jerarquizar y agrupar la información. Las imágenes son el principal recurso y se puede acceder a ellas a través de los textos introductorios, los temas y los manuscritos.

\subsection{Monográficas}

- Título: Jesuits and the Sciences, 1540-1995.

- URL: http://www.luc.edu/libraries/science/jesuits/index.html

- Lengua: inglés.

- Fecha de consulta: 28/10/01.

- Institución: Loyola University of Chicago.

- Contenido: Una exposición de obras raras de tema científico procedentes de la colección jesuítica Cudahy. Característica notable de la Compañía de Jesús durante el período de su primera fundación (1540-1773) fue la implicación de sus miembros en las ciencias. Las razones de este interés en el estudio científico se pueden encontrar en la naturaleza y misión de la orden. Santo Ignacio de Loyola consideraba la adquisición del conocimiento y el trabajo en el mundo como tarea espiritual provechosa, y esto fomentó en la Compañía una orientación hacia el estudio científico. También su extensión por Asia y América dieron oportunidad a los jesuitas de conocer y estudiar estos lugares geográficos. La portada está formada por el título y subtítulo y dos grabados de retratos de los autores jesuitas: Christoph Clavius y Athanasius Kircher. El catálogo de las obras expuestas está organizado en seis periodos cronológicos comprendidos entre $1540 \mathrm{y}$ 1995. Cada apartado contiene varios autores y de cada uno muestra imágenes de las obras expuestas que se pueden ampliar, referencias bibliográfica y un comentario. Se incluyen 20 imágenes de 23 obras de los siglos XVI al XIX. También se reproducen retratos de algunos de los autores. Cada división del catálogo está en una página distinta, así como el resto de los apartados y la portada. En todas se emplea un fondo gris granulado. Predominan los colores blanco, gris y negro.

- Otros apartados: introducción, bibliografía y un índice de autores.

\subsection{Encuadernaciones}

- Título: Bound to Please: Fine Leather Bindings.

- URL: http://www.library.miami.edu/archives/bound/intro.html

- Lengua: inglés.

- Fecha de consulta: 1/11/01.

- Institución: University of Miami.

- Contenido: Exposición dedicada a mostrar una selección de 70 encuadernaciones de obras de la Universidad de Miami. Se describen e ilustran un grupo de encuadernaciones del

Scire. 8: 1 (en.-jun. 2002) 157-172. 
siglo XV hasta el XX de libros realizados en Estados Unidos, Cuba, España, Francia, Alemania, Italia y Holanda. La exposición destaca los intrincados procesos técnicos requeridos para producir las exquisitas y acabadas encuadernaciones. Se ilustran las diversas técnica y estilos. Se inicia con una página índice, decorada en la parte superior con varias imágenes de encuadernaciones. Las obras que forman el catálogo se distribuyen en una sola página, organizada en forma de listado y ordenada en distintos apartados temáticos en función de los diferentes tipos de encuadernación. Cada uno de los apartados reúne información sobre la técnica o el tipo de encuadernación a la que se dedica, referencias bibliográficas de las obras (autor, título, lugar de publicación, editor, año, páginas, dimensiones y notas) y comentarios sobre la encuadernación de cada ejemplar. En total se incluyen 38 imágenes de las encuadernaciones, las cuales se pueden ampliar.

- Otros elementos: selección bibliográfica, un índice de encuadernadores (ordenados alfabéticamente y haciendo referencia al número secuencial de las obras); índice cronológico (las obras ordenadas por años), una adenda, con seis obras añadidas a la exposición, de las que se indican los mismos datos. Incluye también enlaces a archivos y colecciones especiales, a la Biblioteca Otto G. Richter y a la Universidad de Miami.

\subsection{Ilustraciones e iconografía}

- Título: Accent on Images the language of illustrated books.

- URL: http://voxlibris.claremont.edu/sc/events/accent/Lo_AccentonImages.htm

- Lengua: inglés.

- Fecha de consulta: 7/11/01.

- Institución: Claremont College.

- Contenido: En esta muestra se expone una selección de la colección especial de la Biblioteca del Claremont College. Muestra que se realizó en el Clark Humanities Museum del 6 al 8 de noviembre de 1998, con motivo de la reunión anual de la Pacific Anciant and Modern Language Association (PAMLA) celebrada en el Scripps Colleg. Reúne ejemplos de libros ilustrados en idiomas extranjeros modernos del siglo XV al $\mathrm{XX}$, desde las lenguas habladas y escritas en Escandinavia hasta las de la Península Ibérica o Japón. Respecto a los temas, se extienden desde las erupciones volcánicas hasta las visiones del infierno. El catálogo está distribuido en apartados cronológicos: siglos XV al XVI, siglo XVII, siglo XX (1901-1950) y siglo XX (1951-1996). En cada apartado las obras se disponen de forma correlativa en una sola página con estos datos: referencia bibliográfica, imágenes ampliables de la obra, breve comentarios, enlaces a otras web relacionadas y a otros apartados de esta exposición. En total se muestran 25 ilustraciones de 20 obras.

- Otros apartados: texto introductorio de Judy Hervay Sahak con enlaces al Scripps College Press y a la Pacific Ancient and Modern Language Association (PAMLA). Este texto de introducción se dispone a continuación del título en la primera pagina, debajo el índice con las secciones del catálogo. En esta primera página destaca la reproducción de una magnífica orla miniada, en el margen izquierdo.

Scire. 8: 1 (en.-jun. 2002) 157-172. 


\subsection{De un libro}

- Título: Book of Hours.

- URL: http://www.library.brandeis.edu/specialcollections/specialevents/ BookofHours/index.html

- Lengua: inglés.

- Fecha de consulta: 3/11/01.

- Institución: Brandeis University.

- Contenido: Esta muestra está dedicada al "Libro de las horas" del siglo XV perteneciente a la colección especial de la Brandeis University. Fue adquirido en los años 50 por un coleccionista americano, Philip Sang, y donado a esta Institución. Philip Sang era un miembro del Brandeis Bibliophiles, un grupo filantrópico dedicado a conseguir obras para las colecciones especiales de la biblioteca de esta Universidad. La web incluye por tanto el facsímil digital completo de este libro, disponible desde mayo de 1999. Obra compuesta para el rezo de las Horas de la Virgen en una diócesis de Bretaña. La portada de inicio presenta el título, una ilustración y un índice con las tres opciones de acceso a la obra: "texto e iluminaciones", "sólo iluminaciones" e "historia y descripción del Libro de las horas". En la primera opción el texto aparece agrupado en apartados. Cada uno contiene diez páginas en pequeño formato que se pueden ampliar. En la segunda se recogen diez iluminaciones. En la opción dedicada a la historia y descripción, se incluyen enlaces a distintas páginas dedicadas al estudio de esta obra. El fondo de las páginas es negro, para las letras se emplean los colores rojo y amarillo, algunas letras son de estilo gótico.

\subsection{Museos sobre la elaboración del papel}

- Título: Museum of papermaking.

- URL: http://www.ipst.edu/amp/

- Lengua: inglés.

- Fecha de consulta: 5/11/01.

- Institution: Institute of Paper Science and Technology.

- Contenido: Este museo americano, también denominado con el nombre de Roberto C. Williams, está dedicado a la fabricación de papel. Es un recurso internacionalmente citado en la historia del papel y de la tecnología del papel. Además de más de 2.000 libros, el museo ofrece una colección notable de 10.000 filigranas, papeles, herramientas, máquinas y manuscritos. Se inicia con una portada que alberga el índice y un texto de presentación. El recorrido por las obras se realiza a través del apartado "Virtual tour", diseñado mediante la reproducción de la planta del museo (figura 2), en la que se señalan con letras las secciones temáticas del recorrido. Si las pulsamos accedemos a estas secciones, que incluyen textos explicativos con algunas imágenes de los elementos expuestos. Debajo de la planta se ha dispuesto un índice, a través del cual también podemos acceder a cada una de las secciones: "Antecedentes del papel", "Invención del papel", "Difusión de la fabricación del papel por Europa", "Fabricación del papel", "Dard Hunter", "Introducción de la fabricación del papel en Estados Unidos", "Llegada

Scire. $8: 1$ (en.-jun. 2002) 157-172. 
de la máquina del papel", "Galería de exposiciones H. Changing”, "Filigranas", "El moderno molino de papel", "El papel en nuestras vidas", "La industria del reciclado del papel" y "Tienda del museo". Otro apartado que se ha introducido en esta web es un formulario para seleccionar el acceso a las opciones: "recorrido virtual", "galería de exposiciones", "recorrido por la exposición", "futuras exposiciones", "guías para las visitas", "ventajas para los miembros", "otros sitios relacionados", "localización" y "noticias". El índice de la web del Institute of Paper Science and Technology se muestra en todas las páginas.

\subsection{Museos sobre la imprenta}

- Título: Musée de l'imprimerie de Lyon.

- URL: http://www.bm-lyon.fr/musee/imprimerie.htm

- Lengua: francés.

- Fecha de consulta: 7/11/01.

- Institución: Musée de l'imprimerie de Lyon.

- Contenido: En esta web se incluye una amplia información relacionada con la imprenta, de fácil acceso y dirigida a un público muy variado: hay secciones especialmente pensadas para escolares con actividades para que se familiaricen con la imprenta y las técnica gráficas; junto a otras dirigidas a investigadores y especialistas. Al acceder a esta dirección se visualiza en primer lugar una página a modo de portada en la que se va componiendo y descomponiendo el nombre del museo formado por letras que reproducen las de una caja de imprenta. A continuación, se dirige al visitante a una página de bienvenida con información general sobre el museo y sobre las actividades y exposiciones

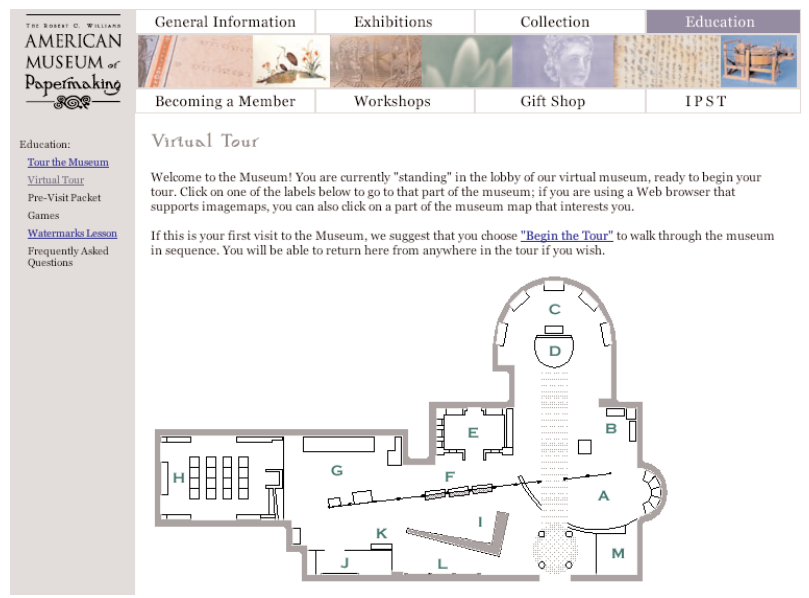

Figura 2. Museum of Papermaking.

Scire. 8: 1 (en.-jun. 2002) 157-172. 
que organiza. La parte más destacada de la web es Une visite virtuel, donde se inicia el recorrido por las obras. Esta sección ofrece una historia de la imprenta y de las técnicas gráficas, también reagrupa algunos de los elementos de la colección permanente del museo en los siguientes apartados: "Los inicios: el libro y sus orígenes", "Evolución intelectual e ideológica", "Progresos técnicos", "El papel", "La letra impresa", "La imagen impresa". Otros apartados están dedicados al centro de documentación del museo, a productos elaborados por el museo (publicaciones, etc.) y a recopilación de enlaces a otros lugares relacionados. En el diseño se recurre al empleo de frames. En todas las páginas permanece fijo el índice general y en una pantalla central se va visualizando el contenido de las distintas secciones. Los colores elegidos son grises, negro y blanco.

\section{Conclusiones}

Hemos comprobado un contraste entre el número de sitios dedicados a museos virtuales en comparación con el de las exposiciones virtuales: 13 de museos frente a 122 de exposiciones. De estas 122 exposiciones, la distribución por materias es la que sigue: mapas y cartografía, 17; música, 1; colecciones, 17; manuscritos, 7; tesoros, 14; de tema histórico, 14; monográficas, 30; ilustraciones e iconografía, 12; encuadernaciones, 5; y de un libro, 5.

Los países que destacan como promotores de estos recursos son Estados Unidos, Gran Bretaña, Francia y España. En las exposiciones están representadas grandes bibliotecas nacionales: Biblioteca del Congreso, Biblioteca Nacional de Francia, Biblioteca Británica, Biblioteca Nacional de España o Biblioteca Nacional de Canadá. Estas bibliotecas han incluido en sus web un apartado dedicado a las exposiciones virtuales organizadas. Se están empleando como una nueva actividad de extensión cultural. También destacan las siguientes universidades: Universidad de Glasgow, Universidad de Virginia, Universidad de Southen Maine y Universidad de Pennsylvania. Gran parte de las exposiciones virtuales son versiones en línea de muestras presenciales.

Los libros y documentos reproducidos en estas web no suelen aparecer a texto completo, a lo sumo dos o tres páginas, casi siempre las de mayor valor artístico. Sin embargo, las muestras dedicadas a un solo libro sí reproducen la obra completa. Frente a esta limitación, las exposiciones y museos en línea presentan una ventaja fruto de su carácter hipertextual, a saber, la ausencia de cierre del hipertexto electrónico, que permite acceder a otros recursos e informaciones relacionadas: la permanente abertura del texto al lector acaba con la expectativa de un fin que proviene de la narrativa tradicional. Las múltiples conexiones posibles permiten conocer nuevas fuentes, pero también tienen el inconveniente de estimular al lector a comenzar a leer un nuevo texto antes de finalizar el anterior y esto conlleva incertidumbres relativas al fin del texto, a la cantidad que fue leída y a lo que aún resta por leer (Murad, 2001). Esta nueva modalidad de exposición

Scire. 8: 1 (en.-jun. 2002) 157-172. 
evita los riesgos de deterioro denunciados por algunos especialistas poco partidarios de las exposiciones bibliográficas presenciales: "Las exposiciones bibliográficas son útiles, pero el beneficio cultural que se obtiene de ellas puede, en ocasiones, no compensar el daño que sufren los frágiles materiales bibliográfico" (Marsá, 1999). Asimismo, las nuevas tecnología permiten reproducir las imágenes reduciendo ampliamente los costes de producción y distribución de estas publicaciones con respecto a la publicación impresa.

Por tanto, no nos debe sorprender que el patrimonio bibliográfico sea objeto destacado de iniciativas de este tipo. Este patrimonio está rodeado de una serie de circunstancias que lo hacen idóneo para someterlo a los procesos que hoy en día permiten las nuevas tecnologías, como por ejemplo los planes de digitalización y de acceso en línea. Frecuentes problemas de conservación inherentes a estos documentos, la riqueza artística de muchos de ellos y las dificultades para su consulta y reproducción pueden explicar que entre las iniciativas más atractivas y de mayor relieve realizadas hasta ahora a través de Internet se encuentre piezas singulares del patrimonio bibliográfico y documental universal.

\section{Referencias bibliográficas}

La Biblioteca de la Universidad Complutense en la exposición "Ex Libris Universitatis". URL: 〈http://www.ucm.es/BUCM/Exlibrisuniversitatis.htm>. Consultado: 19/03/01.

Codina, Lluis( 2000). Parámetros e indicadores de calidad para la evaluación de recursos digitales. // La gestión del conocimiento: retos y soluciones de los profesionales de la información: actas de las VII Jornadas Españolas de Documentación, FESABID 2000, Bilbao, 29, 30, 31 de octubre de 1998. Madrid: FESABID, 2000.

Marsá, María (1999). El fondo antiguo en la biblioteca. Gijón: Ediciones Trea, 1999.

Murad, Angele (2001). El hipertexto, base para reconfigurar la actividad periodística. // Sala de Prensa. Web para profesionales de la Comunicación Iberoamericanos. 34:III, 2 (Agosto 2001). URL: 〈http: //www. saladeprensa. org/art252.htm>. Consultado: 20/11/01.

Rosales, María Helena; Villén, Luis (2000). El acceso y difusión de las colecciones de fondo antiguo: entre la tradición y la modernidad. // Profesionales para una sociedad informada. XI Jornadas Bibliotecarias de Andalucía, Sevilla, 18-19-20 mayo 2000. Málaga: Asociación Andaluza de Bibliotecarios, 2000.

Santos, Ana. La digitalización y las fuentes históricas. URL: <http: //clio.rediris. es/articulos/digital.htm>. Consultado: 23/11/01.

Velasco, Esperanza; Merlo, José Antonio (2000). Nuevas formas para el acceso al libro antiguo. // XV Coloquio de la AIB: Salamanca, 9-11 mayo, 2000. URL: <http: //exlibris. usal. es/merlo/escritos/>. Consultado: 22/11/01. 